\title{
Revision of the Structure Assigned to the Antibiotic BU-4664L from Micromonopora
}

\author{
Yasuhiro Igarashi, Satoshi Miyanaga, Hiroyasu Onaka, Michinori Takeshita, \\ Tamotsu Furumai
}

Received: February 8, 2005 / Accepted: April 22, 2005

(C) Japan Antibiotics Research Association

\begin{abstract}
The structure assigned to the antitumor antibiotic BU-4664L from Micromonospora sp. was revised to 5,10-dihydro-4,6,8-trihydroxy-10-(3,7,11-trimethyltrans-2,trans-6,10-dodecatrienyl)- $11 H$-dibenzo[b,e][1,4]diazepin-11-one based on the NMR analysis.
\end{abstract}

Keywords BU-4664L, antitumor, Micromonospora

In the screening of antitumor compounds from rare actinomycetes, Micromonospora sp. TP-A0860 was found to produce BU-4664L [1] and rakicidins [2]. BU-4664L was originally isolated from Micromonospora sp. M990-6 as a lipoxygenase inhibitor and was shown to have potent in

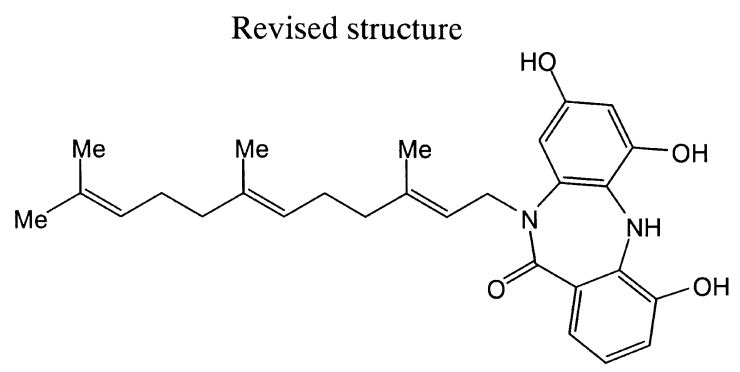

vitro and in vivo antitumor activity. The structure of BU4664L is described in a patent as shown (Fig. 1). During the structural confirmation of the compounds produced by strain TP-A0860, we found that the proposed structure of BU-4664L was incorrect. We herein report the revision of the structure of BU-4664L on the basis of NMR analysis.

The producing strain was isolated from a soil sample collected in Osawano, Toyama, Japan and identified as Micromonospora sp. based on the taxonomic study. Seed and production fermentation was carried out in V-22 and A-3M medium, respectively, as described previously [3]. The fermentation broth (5 liters) was extracted with 1butanol and the organic layer was concentrated in vacuo. The oily extract $(17 \mathrm{~g})$ was successively chromatographed on the column of silica gel $\left(\mathrm{CHCl}_{3}-\mathrm{MeOH} ; 20: 1 \sim 1: 1\right)$, ODS $\left(\mathrm{CH}_{3} \mathrm{CN}-0.15 \% \mathrm{KH}_{2} \mathrm{PO}_{4}, \mathrm{pH} 3.5 ; 20: 80 \sim 85: 15\right)$

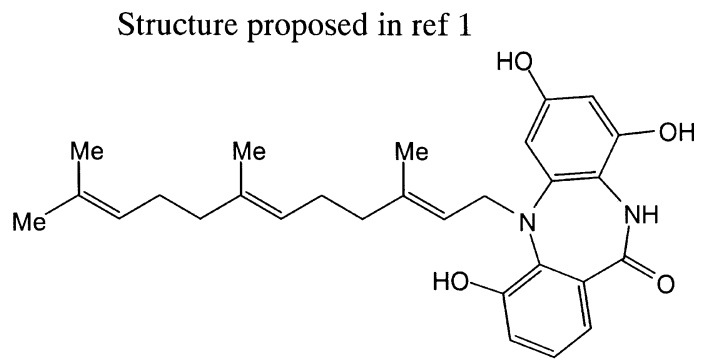

Fig. 1 Structure of BU-4664L.

Y. Igarashi (Corresponding author), S. Miyanaga, H. Onaka, T. Furumai: Biotechnology Research Center, Toyama Prefectural University, 5180 Kurokawa, Kosugi, Toyama 939-0398, Japan, E-mail: yas@pu-toyama.ac.jp
M. Takeshita: Department of Chemistry and Applied Chemistry, Faculty of Science and Engineering, Saga University, Honjo-1, Saga 840-8502, Japan 


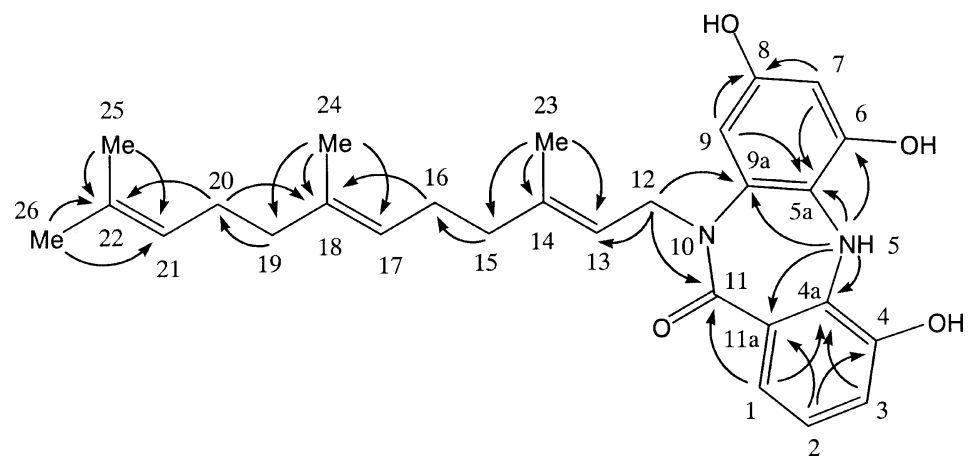

Fig. 2 Important HMBC correlations observed in BU-4664L.

and $\mathrm{LH}-20(\mathrm{MeOH})$ to afford BU-4664L $(16 \mathrm{mg})$ as light yellow needles with the melting point of $192 \sim 194^{\circ} \mathrm{C}$.

The IR spectrum indicated the presence of an amide $\left(1620 \mathrm{~cm}^{-1}\right)$ and hydroxyl $\left(3250 \mathrm{~cm}^{-1}\right)$ groups. The UV-vis spectrum showed the absorption maxima $\lambda_{\max }(\varepsilon)$ at 211 $(45,600)$ and $292(\mathrm{sh})$ in $\mathrm{MeOH}$ or $0.01 \mathrm{~N} \mathrm{HCl}-\mathrm{MeOH}$, and at $206(30,800), 252(\mathrm{sh}), 282(\mathrm{sh}), 344(8,500), 550$ $(2,200)$ in $0.01 \mathrm{~N} \mathrm{NaOH}-\mathrm{MeOH}$. These properties closely resemble to the data described for BU-4664L in ref 1 . The high resolution EI-MS indicated a molecular formula $\mathrm{C}_{28} \mathrm{H}_{34} \mathrm{~N}_{2} \mathrm{O}_{4} \quad\left[m / z \quad 462.2518\left(\mathrm{M}^{+}\right) ; 462.2519\right.$ calcd. for $\mathrm{C}_{28} \mathrm{H}_{34} \mathrm{~N}_{2} \mathrm{O}_{4}$ ]. ${ }^{1} \mathrm{H}$ and ${ }^{13} \mathrm{C}$ NMR spectra in DMSO- $d_{6}$ are also in good accordance with the ones in ref 1 . The ${ }^{13} \mathrm{C}$ NMR spectrum showed 28 carbons assignable to four methyl, five methylene, eighteen $s p^{2}$ and one carbonyl carbon (Table 1). Of these, fifteen carbons (four methyl, five methylene and six $s p^{2}$ carbons) were assigned to a farnesyl residue based on the HMQC and HMBC analysis (Fig. 2). The remaining carbons were assigned to the aromatic chromophore by the HMBC analysis. The $\mathrm{NH}$ proton at $6.72 \mathrm{ppm}$ showed $\mathrm{HMBC}$ correlations to aromatic carbons at C-4a, C-5a, C-6, C-9a and C-11a. On the other hand, HMBC correlations were observed from the metacoupled protons $\mathrm{H}-7$ and $\mathrm{H}-9$ to $\mathrm{C}-5 \mathrm{a}$ and $\mathrm{C}-8$. In addition, DQF-COSY revealed the contiguous coupling of three aromatic protons $\mathrm{H}-1, \mathrm{H}-2$ and $\mathrm{H}-3$ and $\mathrm{HMBC}$ correlations were detected from $\mathrm{H}-1$ and $\mathrm{H}-3$ to $\mathrm{C}-4 \mathrm{a}$ and H-2 to C-4 and C-11a. Substitution of the farnesyl residue on the amido nitrogen at position 10 was unambiguously determined by the HMBC correlations from the C-12 methylene $\left(\delta_{\mathrm{H}} 4.38 ; \delta_{\mathrm{C}} 47.8\right)$ to $\mathrm{C}-9 \mathrm{a}$ and the carbonyl carbon $\mathrm{C}-11$. Although the direct comparison with the authentic compound of BU-4664L was not possible, our spectral data strongly indicate that the compound produced by strain TP-A0860 is identical with BU-4664L. We thus propose that the structure assigned for BU-4664L in ref. 1 should be revised to 5,10-dihydro-4,6,8-trihydroxy-10-
Table 1 NMR assignment for BU-4664L (DMSO- $d_{6}$ )

\begin{tabular}{|c|c|c|}
\hline Position & $\delta^{13} \mathrm{C}$ & $\delta^{1} \mathrm{H}$ \\
\hline 1 & 122.3 & $7.06(1 \mathrm{H}, \mathrm{d}, 7.8 \mathrm{~Hz})$ \\
\hline 2 & 120.4 & $6.70(1 \mathrm{H}, \mathrm{t}, 7.6 \mathrm{~Hz})$ \\
\hline 3 & 116.5 & $6.82(1 \mathrm{H}, \mathrm{d}, 7.8 \mathrm{~Hz})$ \\
\hline 4 & 145.5 & \\
\hline $4 a$ & 141.1 & \\
\hline $5 a$ & 124.8 & \\
\hline 6 & 147.6 & \\
\hline 7 & 100.4 & $6.15(1 \mathrm{H}, \mathrm{d}, 2.2 \mathrm{~Hz})$ \\
\hline 8 & 153.0 & \\
\hline 9 & 99.4 & $6.17(1 \mathrm{H}, \mathrm{d}, 2.2 \mathrm{~Hz})$ \\
\hline $9 a$ & 134.9 & \\
\hline 11 & 167.6 & \\
\hline $11 a$ & 124.8 & \\
\hline 12 & 47.8 & $4.38(2 \mathrm{H}, \mathrm{d}, 6.1 \mathrm{~Hz})$ \\
\hline 13 & 121.6 & $5.24(2 \mathrm{H}, \mathrm{t}, 5.8 \mathrm{~Hz})$ \\
\hline 14 & 136.9 & \\
\hline 15 & 39.0 & $1.98(2 \mathrm{H})$ \\
\hline 16 & 25.9 & $2.00(2 \mathrm{H})$ \\
\hline 17 & 123.7 & $5.05(2 \mathrm{H}, \mathrm{t}, 6.1 \mathrm{~Hz})$ \\
\hline 18 & 134.6 & \\
\hline 19 & 39.2 & $1.89(1 \mathrm{H}), 1.98(1 \mathrm{H})$ \\
\hline 20 & 26.2 & $1.90(1 \mathrm{H}), 1.98(1 \mathrm{H})$ \\
\hline 21 & 124.2 & $5.03(2 \mathrm{H}, \mathrm{t}, 7.1 \mathrm{~Hz})$ \\
\hline 22 & 130.6 & \\
\hline 23 & 16.2 & $1.64(3 \mathrm{H}, \mathrm{s})$ \\
\hline 24 & 15.8 & $1.54(3 \mathrm{H}, \mathrm{s})$ \\
\hline 25 & 17.5 & $1.51(3 \mathrm{H}, \mathrm{s})$ \\
\hline 26 & 25.5 & $1.60(3 \mathrm{H}, \mathrm{s})$ \\
\hline $5-\mathrm{NH}$ & & $6.72(1 \mathrm{H}, \mathrm{s})$ \\
\hline $4-\mathrm{OH}$ & & $9.04^{*}(1 \mathrm{H}$, br.s $)$ \\
\hline $6-\mathrm{OH}$ & & $9.97^{*}(1 \mathrm{H}$, br.s $)$ \\
\hline $8-\mathrm{OH}$ & & $10.05^{*}(1 \mathrm{H}$, br.s $)$ \\
\hline
\end{tabular}

Spectra were recorded in DMSO- $d_{6}$ at $400 \mathrm{MHz}$ for ${ }^{1} \mathrm{H}$ and $100 \mathrm{MHz}$ for ${ }^{13} \mathrm{C}$; solvent peaks were used as a reference $\left(\delta_{\mathrm{H}} 2.50 ; \delta_{\mathrm{C}} 39.5\right)$.

* interchangeable 
(3,7,11-trimethyl-trans-2,trans-6,10-dodecatrienyl)-11Hdibenzo[b,e][1,4]diazepin-11-one.

\section{References}

1. Okumura H, Kobaru S. (Bristol-Meyers Squibb Co.): Compound produced by a strain of Micromonospora. U.S. $5,541,181$, July 30 (1996)
2. MacBrien KD, Berry RL, Lowe SE, Neddermann KM, Bursuker I, Huang S, Klohr SE, Leet JE. Rakicidins, new cytotoxic lipopeptides from Micromonospora sp. Fermentation, isolation and characterization. J Antibiot 48: 1446-1452 (1995)

3. Igarashi Y, Iida T, Yoshida R, Furumai T. Pteridic acids A and $\mathrm{B}$, novel plant growth promoters with auxin-like activity from Streptomyces hygroscopicus TP-A0451. J Antibiot 55: 764-767 (2002) 